\title{
Isolamento biomonitorado de uma substância tripanossomicida de Arrabidaea triplinervia (Bignoniaceae), o ácido ursólico
}

\author{
Leite, J.P.V. ${ }^{1 *}$; Lombardi, J.A. ${ }^{2}$; Chiari, E. ${ }^{3}$, Oliveira, A.B. ${ }^{1}$ \\ ${ }^{1}$ Faculdade de Farmácia; \\ 2 Departamento de Botânica, ICB; ${ }^{3}$ Departamento de Parasitologia, ICB; \\ Universidade Federal de Minas Gerais.
}

\begin{abstract}
RESUMO: Como estratégia para a busca de novos agentes tripanossomicidas, de potencial utilização no controle da transmissão transfusional da doença de Chagas, realizou-se uma triagem dos extratos etanólicos provenientes de espécies vegetais da família Bignoniaceae. Foram avaliadas diferentes metodologias de fracionamento dos extratos etanólicos, tais como, partição entre solventes imiscíveis, cromatografias em coluna de poliamida e de gel de sílica, com monitoramento por testes in vitro contra formas tripomastigotas do Trypanosoma cruzi. Os fracionamentos em coluna de gel de sílica do extrato etanólico das folhas de Arrabidaea triplinervia e, posteriormente, da fração eluída desta coluna com diclorometano-acetato de etila $(1: 1)$ resultaram no isolamento de uma substância tripanossomicida, o ácido ursólico (0,76\%).
\end{abstract}

Unitermos: Bignoniaceae; Arrabidaea triplinervia; Arrabidaea pulchra; Trypanosoma cruzi.

\section{INTRODUÇÃO}

A doença de Chagas é causada pelo protozoário Trypanosoma cruzi, afetando cerca de 16 milhões de pessoas em vários países da América do Sul (DIAS e BRENER, 1984). No Brasil, a transmissão pelo vetor está sob controle e a transfusão sangüínea está se tornando o principal mecanismo de transmissão (SILVEIRA e REZENDE, 1994). Desde a década de 50 , a solução de violeta de genciana vem sendo utilizada como agente quimioprofilático para a esterilização do sangue, mas existem restrições ao seu uso, devido à sua toxicidade para alguns componentes do sangue (NUSSENZWEIG et al., 1953). A busca de novos agentes tripanossomicidas a partir de plantas é uma estratégia válida e importante (CROFT et al., 1988). Vários produtos naturais tripanossomicidas estão descritos na literatura (CHIARI et al., 1996; OLIVEIRA et al., 1996), sendo que alguns desses podem ser considerados como promissores. Entre estes estão $\beta$-lapachona e 3-alil- $\beta$-lapachona, um derivado semi-sintético da $\beta$-lapachona, embora a utilização destas como agente quiomioprofilático seja limitada devido a sua baixa solubilidade em água (SEPULVEDABOZA e CASSELS, 1996).

Com o objetivo de se obter novos agentes tripanossomicidas, foi realizada uma triagem de extratos vegetais através de testes in vitro contra a forma tripomastigota do T. cruzi, visando o

Revista Brasileira de Farmacognosia, V. 11, n. 2, p. 77-87, 2001. 
isolamento de substâncias tripanossomicidas. A etapa inicial desse estudo biomonitorado consistiu na avaliação in vitro de extratos etanólicos contra o T. cruzi. Esta metodologia apresenta, no entanto, alguns inconvenientes que podem interferir nos resultados, tais como a baixa solubilidade de componentes de extratos vegetais no meio aquoso e a hemólise, que pode ser provocada por substâncias presentes nos extratos, sendo necessário, então, um tratamento preliminar dos extratos etanólicos.

Neste presente trabalho, os extratos etanólicos de duas espécies da família Bignoniaceae, Arrabidaea triplinervia H. BAILL e A. pulchra (CHAM.) SANDW, foram testados in vitro contra formas tripomastigotas do $T$. cruzi e submetidos a diferentes metodologias de fracionamento, com monitoramento pelos testes biológicos.

\section{MATERIAIS E MÉTODOS}

\section{Obtenção dos extratos}

As partes aéreas de A. triplinervia e A. pulchra foram coletadas no Campus da Universidade Federal de Minas Gerais, em março de 1994. Folhas e caules foram separados e secos em estufa ventilada a $38^{\circ} \mathrm{C}$, sendo, em seguida, pulverizados em moinho. Os pós das diferentes partes das plantas foram submetidos a extrações exaustivas com etanol $96^{\circ} \mathrm{GL}$, por percolação, e as soluções obtidas foram concentradas em evaporador rotatório. As massas dos pós das plantas e as dos extratos estão indicadas na Tabela 1.

TABELA 1. Massas dos pós das plantas e dos seus respectivos extratos etanólicos.

\begin{tabular}{l|l|c|c|c}
\hline $\begin{array}{l}\text { Espécies } \\
\text { Vegetais }\end{array}$ & Parte & $\begin{array}{c}\text { Massa do pó da } \\
\text { planta (g) }\end{array}$ & $\begin{array}{c}\text { Massa do } \\
\text { extrato (g) }\end{array}$ & $\begin{array}{c}\text { Rendimento } \\
\mathbf{( \% )}\end{array}$ \\
\hline $\begin{array}{l}\text { Arrabidaea } \\
\text { triplinervia }\end{array}$ & Folhas & 270,3 & 49,0 & 18,0 \\
\hline $\begin{array}{l}\text { Arrabidaea } \\
\text { pulchra }\end{array}$ & Folhas & 178,0 & 13,7 & 7,7 \\
\hline
\end{tabular}

\section{Testes in vitro contra formas tripomastigotas do Trypanossoma cruzi}

Os testes in vitro contra tripomastigotas do $T$. cruzi foram realizados de acordo com a metodologia descrita por CHIARI et al., 1996. Os extratos etanólicos, as frações obtidas a partir destes e a substância pura foram dissolvidos em dimetilsulfóxido (DMSO) $(0,2 \mathrm{ml})$ e meio para cultura de tecido TCM199 (2,0ml). Desta soluçãoasuspensão, foram retiradas alíquotas de 200 , 100,50 e $25 \mu \mathrm{l}$ e, a cada uma delas, adicionou-se sangue infectado $(200 \mathrm{ml})$, completando-se o volume para $500 \mathrm{ml}$ com TCM199. O sangue utilizado nos testes in vitro foi obtido a partir de camudongos infectados com as cepas CL e Y do T. cruzi. Uma densidade parasitária de $2 \times 10^{5}$ tripomastigotasa $0,1 \mathrm{ml}$ foi calculada para cada tubo-teste $(4 \mathrm{ml}, 56 \times 13 \mathrm{~mm})$; tubos-controle contendo DMSO e DMSO + TCM199, sem as amostras e com violeta de genciana foram também avaliados. Após incubação a $4^{\circ} \mathrm{C}$, por $24 \mathrm{~h}$, as suspensões foram microscopicamente examinadas e os resultados descritos como: (-) ausência de parasitas (ativa); (+) redução no número de 
parasitas (parcialmente ativa); (++) número de T. cruzi igual ao controle (inativa); (L) lise de eritrócitos; (ND) não determinado.

\section{Fracionamentos preliminares dos extratos etanólicos}

Diferentes tratamentos dos extratos etanólicos foram realizados e monitorados por testes in vitro contra formas tripomastigotas do Trypanossoma cruzi para avaliação da eficiência dos procedimentos empregados.

\section{Partição entre solventes imiscíveis}

O resíduo de cada extrato etanólico $(1,0 \mathrm{~g})$, retomado em água, foi submetido a partições entre solventes imiscíveis, como mostrado na Figura 1. Amostras (20mg) das frações obtidas foram submetidas aos testes biológicos.

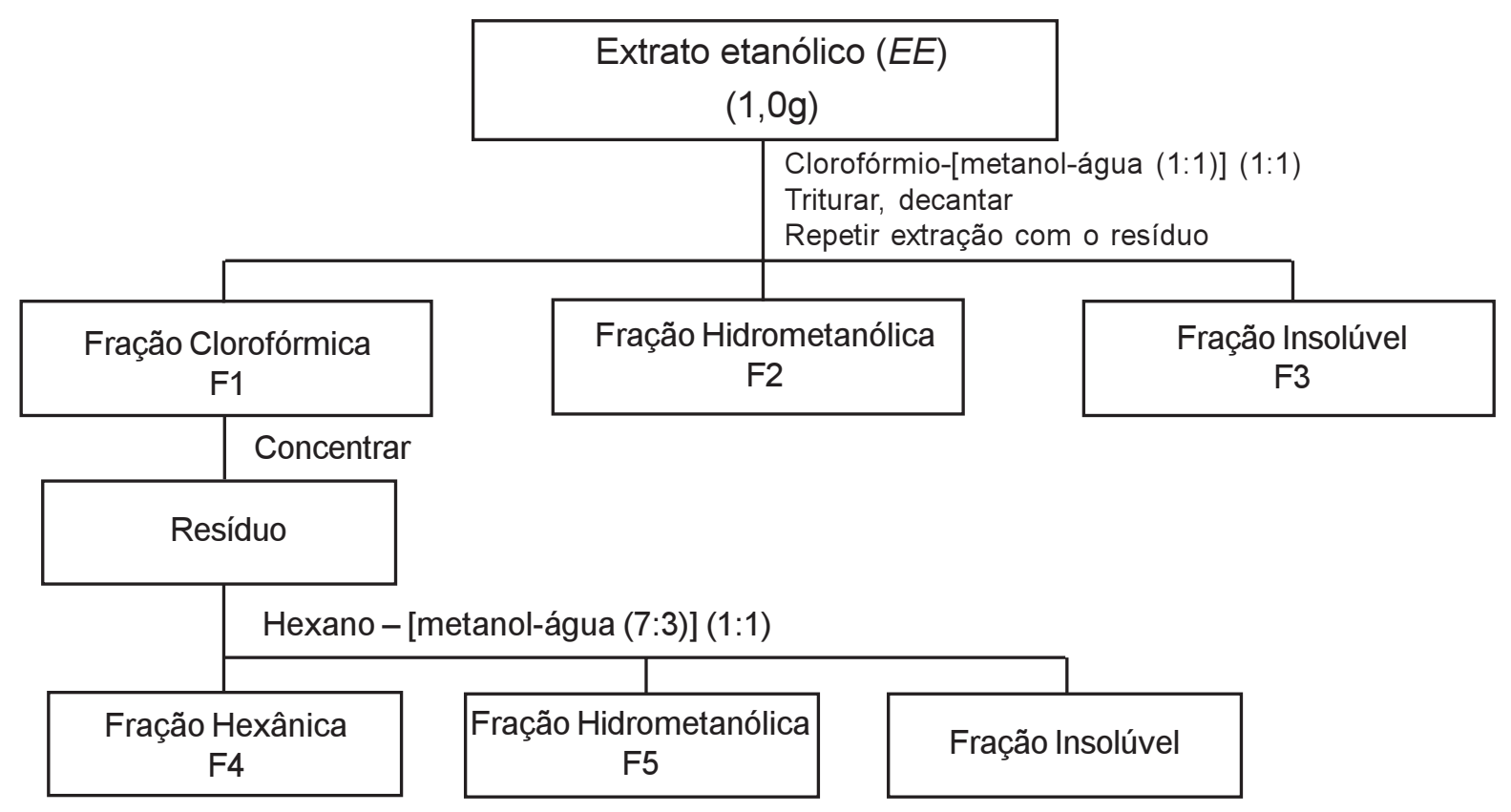

FIGURA 1. Fracionamento preliminar dos extratos etanólicos de Arrabidaea triplinervia e Arrabidaea pulchra por partição entre solventes imiscíveis.

As massas das frações obtidas, após partições entre solventes imiscíveis, a partir dos extratos etanólicos $(1,0 \mathrm{~g})$ de A. triplinervia e A. pulchra, estão expressas na Tabela 2. 
TABELA 2. Massas das frações obtidas por partições entre solventes imiscíveis, a partir dos extratos etanólicos $(1,0 \mathrm{~g})$ de Arrabidaea triplinervia e Arrabidaea pulchra.

\begin{tabular}{c|c|c|c|c|c|c}
\hline \multirow{2}{*}{$\begin{array}{c}\text { Espécies } \\
\text { vegetais }\end{array}$} & Partes da & \multicolumn{5}{|c}{ Massas (mg) } \\
\cline { 3 - 7 } & planta & F1 & F2 & F3 & F04 & F5 \\
\hline $\begin{array}{c}\text { Arrabidaea } \\
\text { triplinervia }\end{array}$ & Folhas & 20 & 400 & 90 & 40 & 250 \\
& Caules & - & 650 & 50 & 70 & 200 \\
\hline $\begin{array}{c}\text { Arrabidaea } \\
\text { pulchra }\end{array}$ & Folhas & 14 & 320 & 120 & 30 & 380 \\
& Caules & - & 310 & 140 & 25 & 420 \\
\hline
\end{tabular}

\section{Cromatografia em coluna de poliamida}

Uma alíquota de cada extrato etanólico $(500 \mathrm{mg})$, previamente dissolvida em metanol, foi cromatografada em uma coluna de poliamida $(15 \times 3 \mathrm{~cm})$, eluindo-se exaustivamente com metanol. O metanol foi completamente removido por destilação, em evaporador rotatório, e uma alíquota do resíduo $(20 \mathrm{mg})$ foi remetida para os testes biológicos. A massa das frações metanólicas obtidas, após filtração em coluna de poliamida, estão apresentadas na Tabela 3.

TABELA 3. Massas das frações metanólicas obtidas após cromatografia em coluna de poliamida dos extratos etanólicos (500mg) de Arrabidaea triplinervia e Arrabidaea pulchra.

\begin{tabular}{c|c|c}
\hline Espécies vegetais & $\begin{array}{c}\text { Partes da } \\
\text { planta }\end{array}$ & Massas $(\mathbf{m g})$ \\
\hline Arrabidaea & Folhas & 401 \\
triplinervia & Caules & 370 \\
\hline Arrabidaea & Folhas & 324 \\
pulchra & Caules & 424 \\
\hline
\end{tabular}

\section{Cromatografia em coluna de gel de sílica}

Uma alíquota do extrato etanólico $(1,5 \mathrm{~g})$ foi submetida à cromatografia em coluna de gel de sílica $(50 \mathrm{~g})$, utilizando-se, os seguintes eluentes na ordem indicada: hexano (F1), diclorometano $(F 2)$, diclorometano-acetato de etila $(1: 1)(F 3)$, acetato de etila (F4) e metanol (F5). A solução correspondente a cada eluente foi concentrada até resíduo, em evaporador rotatório, e uma parte desta $(20 \mathrm{mg})$ foi remetida para os testes biológicos. As massas obtidas de cada fração estão apresentadas na Tabela 4. 
TABELA4. Massas das frações resultantes da cromatografia em coluna de gel de sílica dos extratos etanólicos $(1,5 \mathrm{~g})$ de Arrabidaea triplinervia e Arrabidaea pulchra.

\begin{tabular}{c|c|c|c|c|c|c}
\hline \multirow{2}{*}{$\begin{array}{c}\text { Espécies } \\
\text { vegetais }\end{array}$} & $\begin{array}{c}\text { Partes da } \\
\text { planta }\end{array}$ & \multicolumn{5}{|c}{ Massas (mg) } \\
\cline { 3 - 7 } & & F1 & F2 & F3 & F4 & F5 \\
\hline $\begin{array}{c}\text { Arrabidaea } \\
\text { triplinervia }\end{array}$ & Folhas & 18 & 140 & 220 & 115 & 520 \\
& Caules & 10 & 110 & 160 & 95 & 630 \\
\hline $\begin{array}{c}\text { Arrabidaea } \\
\text { pulchra }\end{array}$ & Folhas & 16 & 60 & 120 & 70 & 740 \\
& Caules & 08 & 45 & 78 & 150 & 980 \\
\hline
\end{tabular}

Isolamento do ácido ursólico por cromatografia em coluna de gel de sílica a partir da fração F3, proveniente do fracionamento do extrato etanólico das folhas de Arrabidaea triplinervia

Uma alíquota (70mg) de F3, eluída com diclorometano - acetato de etila (1:1) da coluna em gel de sílica do extrato etanólico das folhas de A. triplinervia (Tabela 4), foi submetida à cromatografia em coluna de gel de sílica, sendo utilizado o mesmo sistema eluotrópico, descrito anteriormente, obtendo-se nove sub-frações. A sub-fração 2, após recristalização em metanol, forneceu $20 \mathrm{mg}$ do ácido ursólico (Figura 2).

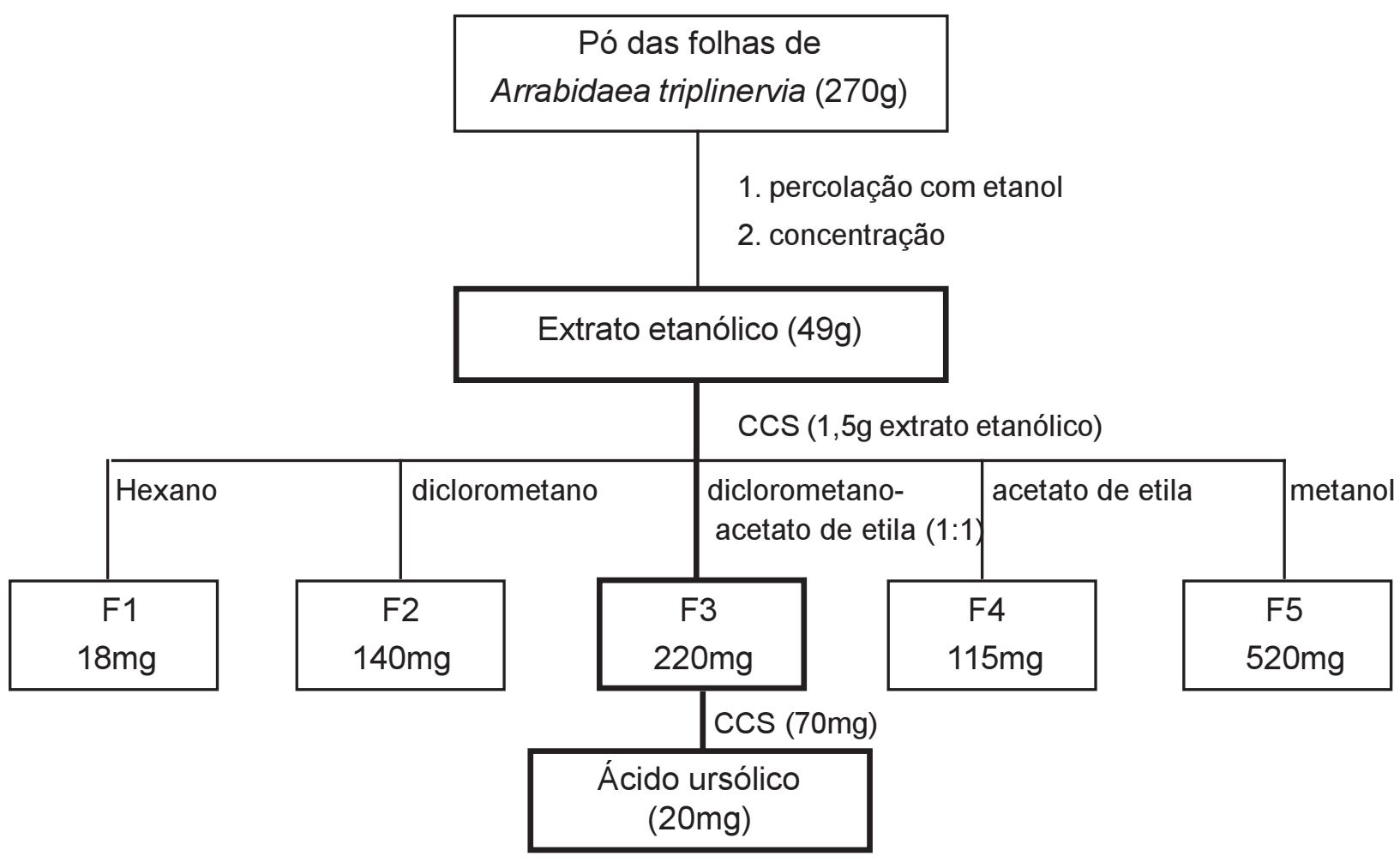

direcionamento da atividade tripanosomicida

FIGURA 2. Fluxograma para o isolamento do ácido ursólico do extrato etanólico das folhas de Arrabidaea triplinervia. 


\section{Identificação do ácido ursólico}

Ácido 3ß-hidróxi-urs-12-en-28-óico: cristais brancos, ponto de fusão $248-250^{\circ} \mathrm{C}$ (lit. 238$240^{\circ} \mathrm{C}$; Lee et al., 1988). Os dados espectrais que permitiram a identificação do ácido ursólico foram obtidos por espectrometrias no infravermelho (IV), de massas com impacto eletrônico (EMIE), ressonância magnética nuclear de hidrogênio $\left(\mathrm{RMN}^{1} \mathrm{H}\right)$ e de carbono-13 $\left(\mathrm{RMN}^{13} \mathrm{C}\right)$.

IV $\mathrm{n}_{\text {máx. }} 3400,2900,1690,1650,1460,990 \mathrm{~cm}^{-1}$; EMIE $\mathrm{m} / \mathrm{z}$ (intensidade relativa) 456 [M] ${ }^{+}$ (3), 248 (100), 207 (23), 203 (35), 133 (26); RMN ${ }^{1} \mathrm{H}$ ( $\mathrm{D}_{6}$-DMSO, 400MHz, d) 5, 13 (t, J3,3Hz, 1H, H12), 4,28 (d, J 5,0Hz, 1H, 3-OH), 2,99 (dt, J 10,1, 5,0 e 5,0Hz, 1H, H-3), 2,12 (d, J 11,3Hz, 1H, H18), 1,04 (s, 3H), 0,90 (d, J 7,7Hz, 3H), 0,89 (s, 3H), 0,87 (s, 3H), 0,81 (d, J6,4Hz, 3H), 0,75 (s, 3H), 0,67 (s, 3H); $\mathrm{RMN}^{13} \mathrm{C}\left(\mathrm{D}_{6}-\mathrm{DMSO}, 100 \mathrm{MHz}\right.$, d) 38,3 (C-1), 27,0 (C-2), 76,8 (C-3), 36,3 (C-4), 54,8 (C-5), 18,0 (C-6), 32,7 (C-7), 39,4 (C-8), 47,0 (C-9), 38,2 (C-10), 22,8 (C-11), 124,6 (C-12), 138,2 (C-13), 41,6 (C-14), 27,5 (C-15), 23,8 (C-16), 46,8 (C-17), 52,4 (C-18), 38,5 (C-19), 38,4 (C-20), 30,2 (C-21), 36,5 (C-22), 28,2 (C-23), 15,2 (C-24), 16,1 (C-25), 16,9 (C-26), 23,3 (C-27), 178,2 (C28), 17,0 (C-29), 21,0 (C-30).

\section{RESULTADOS E DISCUSSÃO}

\section{Triagem dos extratos etanólicos de Arrabidaea triplinervia e Arrabidaea pulchra}

Os resultados dos testes in vitro contra formas tripomastigotas do T. cruzi das amostras dos extratos etanólicos de folhas e caule de A. triplinervia e A. pulchra estão indicados na Tabela 5. O extrato etanólico de folhas de A. triplinervia, na concentração de $5,0 \mathrm{mg} / \mathrm{ml}$, eliminou completamente os parasitas do sangue, e foi parcialmente ativo na concentração de $2,5 \mathrm{mg} / \mathrm{ml}$. Em ambas as concentrações, observou-se lise parcial de eritrócitos. O extrato etanólico do caule desta espécie e aqueles de folhas e caules de A. pulchra foram inativos e não provocaram hemólise.

TABELA 5. Resultados dos testes in vitro dos extratos etanólicos de Arrabidaea triplinervia e Arrabidaea pulchra contra formas tripomastigotas do Trypanossoma cruzi.

\begin{tabular}{c|c|c|c|}
\hline \multirow{2}{*}{$\begin{array}{c}\text { Espécies } \\
\text { Vegetais }\end{array}$} & Partes da planta & \multicolumn{2}{|c}{ Concentrações $(\mathbf{m g} / \mathrm{ml})$} \\
\cline { 2 - 4 } & Folhas & $\mathbf{5 , 0}$ & $\mathbf{2 , 5}$ \\
\hline $\begin{array}{c}\text { Arrabidaea } \\
\text { triplinervia }\end{array}$ & Caules & ++ & $+\mathrm{L}$ \\
\hline $\begin{array}{c}\text { Arrabidaea } \\
\text { pulchra }\end{array}$ & Folhas & ++ & ++ \\
\hline & Caules & ++ & ++ \\
\hline
\end{tabular}

(-) ausência de parasitas (ativa); (+) redução no número de parasitas (parcialmente ativa); (++) número de T. cruzi igual ao controle (inativa); (L) lise de eritrócitos; (ND) não determinado. 


\section{Testes in vitro contra o Trypanossoma cruzi das frações resultantes das partições entre solventes imiscíveis dos extratos etanólicos}

As frações resultantes das partições entre solventes imiscíveis foram ensaiadas nas concentrações de 10,0 e 5,0mg/ml e os resultados são mostrados na Tabela 6. Para Arrabidaea triplinervia, apenas F3-folha foi ativa, com lise parcial de eritrócitos, nas duas concentrações ensaiadas. Para Arrabidaea pulchra, três frações foram ativas, F3 e F5, ambas de folha, e F5caule. Todas as frações ativas, exceto F3-folha, de Arrabidaea pulchra causaram lise parcial de eritrócitos. Porém, esta fração foi ativa apenas na concentração de $10 \mathrm{mg} / \mathrm{ml}$. Estes resultados mostram que um teste negativo com um extrato bruto não exclui a possibilidade de resultado positivo com frações resultantes de diferentes fracionamentos deste, uma vez que algumas frações estarão enriquecidas em substância(s) ativa(s).

TABELA 6. Resultados dos testes in vitro contra o Trypanosoma cruzi das frações resultantes das partições entre solventes imiscíveis dos extratos etanólicos de Arrabidaea triplinervia e Arrabidaea pulchra.

\begin{tabular}{c|c|c|c|c|c|c|c}
\hline $\begin{array}{c}\text { Espécies } \\
\text { vegetais }\end{array}$ & $\begin{array}{c}\text { Partes da } \\
\text { planta }\end{array}$ & $\begin{array}{c}\text { Concentrações } \\
\text { (mg/ml) }\end{array}$ & \multicolumn{5}{|c}{ Frações } \\
\hline $\begin{array}{c}\text { Arrabidaea } \\
\text { triplinervia }\end{array}$ & Folhas & 10,0 & F1 & F2 & F3 & F4 & F5 \\
& Caules & 5,0 & $+\mathrm{L}$ & ++ & $-\mathrm{L}$ & ++ & ++ \\
& 10,0 & ND & ++ & ++ & $+\mathrm{L}$ & ++ \\
& & 5,0 & ND & ++ & ++ & $++\mathrm{L}$ & ++ \\
\hline $\begin{array}{c}\text { Arrabidaea } \\
\text { pulchra }\end{array}$ & Folhas & 10,0 & ND & ++ & - & ++ & $-\mathrm{L}$ \\
& & 5,0 & ND & ++ & + & ++ & $-\mathrm{L}$ \\
& Caules & 10,0 & ND & ++ & ND & ++ & $-\mathrm{L}$ \\
& & 5,0 & ND & ++ & ND & ++ & ++ \\
\hline
\end{tabular}

(-) ausência de parasitas (ativa); (+) redução no número de parasitas (parcialmente ativa); (++) número de T. cruzi igual ao controle (inativa); (L) lise de eritrócitos; (ND) não determinado.

\section{Testes in vitro contra o Trypanossoma cruzi das frações resultantes da cromatografia em coluna de poliamida dos extratos etanólicos}

$\mathrm{Na}$ cromatografia dos extratos etanólicos em coluna de poliamida o único eluente empregado foi o metanol, tendo sido recolhida, em cada caso, uma única fração cujo resíduo, após remoção do metanol, foi submetido aos bioensaios. Os resultados destes constam da Tabela 7. Somente para folhas de Arrabidaea triplinervia observou-se ausência de parasitas, na concentração de $5,0 \mathrm{mg} / \mathrm{ml}$, e redução no número destes, na concentração de $2,5 \mathrm{mg} / \mathrm{ml}$. É interessante chamar a atenção para a ausência de hemólise, em todos os testes realizados, após a filtração em poliamida. Considerando que o único eluente empregado foi o metanol, conclui-se que o(s) agente(s) hemolítico(s) é(são) mais polar(es), não tendo sido eluído(s) da coluna de poliamida, por este solvente. 
TABELA 7. Resultados dos testes in vitro contra o Trypanossoma cruzi das frações resultantes da cromatografia em coluna de poliamida partir dos extratos etanólicos de Arrabidaea triplinervia e Arrabidaea pulchra.

\begin{tabular}{c|c|c|c}
\hline \multirow{2}{*}{ Espécies vegetais } & Partes da planta & \multicolumn{2}{|c}{ Concentrações (mg/ml) } \\
\cline { 2 - 4 } & Folhas & 5,0 & 2,5 \\
\hline $\begin{array}{c}\text { Arrabidaea } \\
\text { triplinervia }\end{array}$ & Caules & - & + \\
\hline $\begin{array}{c}\text { Arrabidaea } \\
\text { pulchra }\end{array}$ & Folhas & ++ & ++ \\
\hline
\end{tabular}

(-) ausência de parasitas (ativa); (+) redução no número de parasitas (parcialmente ativa); (++) número de T. cruzi igual ao controle (inativa); (L) lise de eritrócitos; (ND) não determinado.

\section{Testes in vitro contra o Trypanossoma cruzi das frações resultantes da cromatografia em coluna de gel de sílica dos extratos etanólicos}

Outro método utilizado foi o fracionamento do extrato etanólico, em coluna de gel de sílica, o qual foi realizado como descrito anteriormente. Os resultados dos testes realizados com as frações obtidas da coluna de gel de sílica de Arrabidaea triplinervia e A. pulchra estão apresentados, respectivamente, nas Tabelas 8 e 9.

TABELA 8. Resultados dos testes in vitro das frações obtidas da cromatografia em gel de sílica do extrato etanólico de Arrabidaea triplinervia contra formas tripomastigotas do Trypanossoma cruzi.

\begin{tabular}{c|c|c|c|}
\hline \multirow{2}{*}{$\begin{array}{c}\text { Partes da } \\
\text { Planta }\end{array}$} & Fração/Eluente & \multicolumn{2}{c|}{$\begin{array}{c}\text { Concentrações } \\
\text { (mg/ml) }\end{array}$} \\
\hline \multirow{2}{*}{ Folhas } & & 10,0 & 5,0 \\
& F2 / diclorometano & ++ & ++ \\
& F3/ diclorometano-acetato etila (1:1) & - & - \\
& F4 / acetato de etila & ++ & ++ \\
& F5 / metanol & ++ & ++ \\
\hline \multirow{2}{*}{ Caules } & F2 / diclorometano & ++ & ++ \\
& F3 / diclorometano-acetato etila (1:1) & $-\mathrm{L}$ & $-\mathrm{L}$ \\
& F4 / acetato de etila \\
& F5 metanol & ++ & ++ \\
& & ++ & ++ \\
\hline
\end{tabular}

(-) ausência de parasitas (ativa); (+) redução no número de parasitas (parcialmente ativa); (++) número de T. cruzi igual ao controle (inativa); (L) lise de eritrócitos; (ND) não determinado. 
TABELA 9. Resultados dos testes in vitro das frações obtidas da cromatografia em gel de sílica do extrato etanólico de Arrabidaea pulchra contra formas tripomastigotas do Trypanossoma cruzi.

\begin{tabular}{|c|c|c|c|}
\hline \multirow{2}{*}{$\begin{array}{c}\text { Parte da } \\
\text { Planta }\end{array}$} & \multirow{2}{*}{ Fração/Eluente } & \multicolumn{2}{|c|}{$\begin{array}{c}\text { Concentrações } \\
(\mathrm{mg} / \mathrm{ml})\end{array}$} \\
\hline & & 10,0 & 5,0 \\
\hline Folhas & $\begin{array}{c}\text { F2 / diclorometano } \\
\text { F3/ diclorometano-acetato etila }(1: 1) \\
\text { F4 / acetato de etila } \\
\text { F5 / metanol }\end{array}$ & $\begin{array}{l}++ \\
-L \\
N D \\
++\end{array}$ & $\begin{array}{l}++ \\
-L \\
N D \\
++\end{array}$ \\
\hline Caules & $\begin{array}{c}\text { F2 / diclorometano } \\
\text { F3/ diclorometano-acetato etila }(1: 1) \\
\text { F4 / acetato de etila } \\
\text { F5 / etanol }\end{array}$ & $\begin{array}{l}++ \\
-\mathrm{L} \\
+\mathrm{L} \\
++\end{array}$ & $\begin{array}{l}++ \\
+\mathrm{L} \\
+\mathrm{L} \\
++\end{array}$ \\
\hline
\end{tabular}

(-) ausência de parasitas (ativa); (+) redução no número de parasitas (parcialmente ativa); (++) número de T. cruzi igual ao controle (inativa); (L) lise de eritrócitos; (ND) não determinado.

Os resultados das Tabelas 8 e 9 indicam a atividade das frações eluídas com diclorometano - acetato de etila (1:1) (F3) do extrato etanólico das folhas e caules de ambas as espécies sendo que, para as folhas de Arrabidaea triplinervia não foi verificada hemólise, que ocorreu com as demais frações eluídas com esta mesma mistura de eluentes.

As análises por cromatografia em camada delgada das frações ativas, obtidas por diferentes fracionamentos, a partir dos extratos etanólicos de folhas e caules de Arrabidaea triplinervia e Arrabidaea pulchra mostraram a presença de ácido ursólico em todas elas. Conclui-se que o teor desta substância em Arrabidaea pulchra é menor do que em Arrabidaea triplinervia, já que, os extratos brutos da primeira espécie foram inativos nas mesmas condições nas quais aqueles de Arrabidaea triplinervia foram ativos. Por outro lado, após fracionamento, observou-se atividade tripanosomicida para $A$. pulchra, em frações resultantes de partição entre solventes imiscíveis (Tabela 6) e das cromatografias em coluna de poliamida (Tabela 7) e de gel de sílica (Tabela 8). 0 efeito hemolítico causado pelo extrato etanólico das folhas de A. triplinervia (Tabela 5) persistiu na fração ativa F3 (Tabela 6) e apareceu na fração F5 de Arrabidaea pulchra (Tabela 6), enquanto que nos fracionamentos por cromatografia em coluna de gel de sílica este não foi observado para F3folha de Arrabidaea triplinervia.

\section{Identificação do ácido ursólico e avaliação da sua atividade tripanossomicida}

Uma alíquota (70mg) da fração eluída com diclorometano:acetato de etila (1:1) (F3), proveniente do extrato etanólico das folhas de Arrabidaea triplinervia, que provocou eliminação total das formas tripomastigotas do Trypanossoma cruzi, sem provocar lise de eritrócitos (Tabela 8), após cromatografia em coluna de gel de sílica, forneceu $20 \mathrm{mg}$ de uma substância correspondente a $0,76 \%$ de folhas secas de Arrabidaea triplinervia. Análise espectrométrica (IV, EM, RMN ${ }^{1} \mathrm{H}$ e RMN ${ }^{13} \mathrm{C}$ ) e comparação com dados da literatura (LEE et al., 1988) permitiram sua identificação como sendo o ácido ursólico (Figura 3). 
<smiles>C[C@H]1CCC2(C(=O)O)CC[C@]3(C)C(=CCC4[C@@]5(C)CC[C@@H](O)C(C)(C)C5CC[C@]43C)C12</smiles>

FIGURA 3. Estrutura química do ácido ursólico.

O ácido ursólico foi submetido aos testes biológicos, em diferentes concentrações (Tabela 10). Os resultados mostraram a eliminação total do Trypanossoma cruzi (cepa $Y$ ), nas concentrações de 1,$6 ; 0,8$ e $0,4 \mathrm{mg} / \mathrm{ml}$, e, na concentração de $0,2 \mathrm{mg} / \mathrm{ml}$, este composto foi parcialmente ativo. Para a cepa CL, o ácido ursólico foi ativo apenas nas concentrações de 1,6 e 0,8mg/ml.

Várias atividades têm sido relatadas para o ácido ursólico: antiinflamatória, hepatoprotetora, antitumoral, antimicrobiana e outras (LIU, 1995). No entanto, pela primeira vez, no nosso conhecimento, é relatada a atividade de um triterpeno contra formas tripomastigotas do Typanossoma cruzi. A tingenona, um triterpeno quinonóide, mostrou-se ativa contra formas epimastigotas do Trypanossoma cruzi (SEPULVEDA-BOZA e CASSELS, 1996), sendo que a atividade desta substância deve estar relacionada com o núcleo quinonametídeo da substância, enquanto que o ácido ursólico deve atuar por outro mecanismo de ação.

TABELA 10. Resultados dos testes in vitro do ácido ursólico contra formas tripomastigotas do Tripanossoma cruzi.

\begin{tabular}{|c|c|c|c|c|c|}
\hline \multirow{2}{*}{ Substância } & \multirow{2}{*}{$\begin{array}{l}\text { T. cruzi } \\
\text { Cepas }\end{array}$} & \multicolumn{4}{|c|}{ Concentrações $(\mathrm{mg} / \mathrm{ml})$} \\
\hline & & 1,6 & 0,8 & 0,4 & 0,2 \\
\hline \multirow[t]{2}{*}{ Ácido ursólico } & Y & - & - & - & + \\
\hline & CL & - & - & ++ & ++ \\
\hline
\end{tabular}

(-) ausência de parasitas (ativa); (+) redução no número de parasitas (parcialmente ativa);

(++) número de T. cruzi igual ao controle (inativa); (L) lise de eritrócitos; (ND) não determinado.

\section{CONCLUSÃO}

Os testes in vitro dos extratos etanólicos de folhas e caules de A. triplinervia e A.pulchra contra formas tripomastigotas do Trypanossoma cruzi foram positivos apenas para o extrato bruto das folhas de $A$. triplinervia.

Metodologias de fracionamentos de extratos foram aplicadas aos extratos etanólicos de $A$. triplinervia e A. pulchra, tais como, partição entre solventes imiscíveis, cromatografias em colunas de poliamida e de gel de sílica. Estas duas últimas forneceram frações mais ativas em relação ao extrato etanólico de $A$. triplinervia, enquanto que as partições entre solventes imiscíveis e a 
cromatografia em coluna de gel de sílica permitiram a obtenção de frações ativas a partir do extrato bruto de Arrabidaea pulchra, o qual foi inativo na triagem inicial.

Assim, um fracionamento inicial de extratos inativos é também desejável, de forma que se possa avaliar, separadamente, frações contendo compostos com propriedades físico-químicas diferentes e, também, biomonitorar um estudo fitoquímico, com o objetivo de isolar substâncias ativas.

A cromatografia da fração ativa, obtida por fracionamento em coluna de gel de sílica do extrato etanólico das folhas de A. triplinervia, conduziu a uma substância tripanossomicida, o ácido ursólico.

\section{REFERÊNCIAS BIBLIOGRÁFICAS}

CHIARI, E.; RASLAN, D.S.; SAÚDE, D.A.; PERRY, K.S.P.; BOAVENTURA, M.A.D.; GRANDI, T.S.M.; STEHMANN, J.R.; ANJOS, A.M.G.; OLIVEIRA, A.B. In vitro screening of Asteraceae plant species against Trypanosoma cruzi. Phytotherapy Research, n.10, p. 636-638, 1996.

CROFT, S.L.; WALKER, J.J.; GUTTERIDGE, W.E. Screening of drugs for rapid activity against Trypanosoma cruzi trypomastigotes in vitro. Trop. Med. Parasitol., n.39, p. 145, 1988.

DIAS, J.C.P.; BRENER, S. Chagas disease and blood transfusion. Memórias do Instituto Oswaldo Cruz, n. 79, p. 139-147, 1984.

LEE, K.L.; LIN, Y.M.; WU, T.S.; ZHANG, D.C.; YAMAGISHI, T.; HALL, I.H.; WU, R.Y. The cytotoxic principles of Prunella vulgaris, Psychotria serpens and Hyptis capitata: ursolic acid and related derivatives. Planta Medica, n. 54, p. 308-311, 1988.

LIU, J. Pharmacology of oleanolic and ursolic acids. Journal of Ethnopharmacology, n. 49, p. 5768, 1995.

NUSSENZWEIG, V.; SONNTAG, R.; FREITAS, J.P.L.P.; AMATO NETO, V.; BIANCALANA, A. KLOETZEL, J. Ação da violeta de genciana sobre o Trypanossoma cruzi in vitro: sua importância na esterilização do sangue destinado a transfusão. Revista Paulista de Medicina, n. 42, p. 85-86, 1953.

OLIVEIRA, A.B.; CHIARI, E.; SAÚDE, D.A.; PERRY, K.S.P.; DÂMARIS, S.D.; RASLAN, D.S.; BOAVENTURA, M.A.D. Trypanocidal sesquiterpenes from Lychnophora species. Phytotherapy Research, n. 10, p. 292-295, 1996.

SEPULVEDA-BOZA, S.; CASSELS, B.K. Plant metabolites active against Trypanosoma cruzi. Planta Medica, n. 62, p. 98-105, 1996.

SILVEIRA, A.C.; REZENDE, D.F. Epidemiologia e controle da transmissão vetorial da doença de Chagas no Brasil. Revista Brasileira de Medicina Tropical, n. 27, p. 11-22, 1994.

\section{*Autor para correspondência:}

Prof. João Paulo Viana Leite

Laboratório de Fitoquímica

Departamento de Produtos Farmacêuticos

Faculdade de Farmácia

Universidade Federal de Minas Gerais

Av. Olegário Maciel, 2360

30180-112 - Belo Horizonte - MG 